Check for updates

Cite this: RSC Adv., 2018, 8, 3296

Received 23rd October 2017 Accepted 29th December 2017

DOI: $10.1039 / c 7 r a 11675 f$

rsc.li/rsc-advances

\section{Light weight and flexible poly(ether ether ketone) based composite film with excellent thermal stability and mechanical properties for wide-band electromagnetic interference shielding $\dagger$}

\begin{abstract}
Ruiqi $\mathrm{Na}^{\mathrm{a}}$ Jinying Liu, ${ }^{\mathrm{b}}$ Guibin Wang (D) a and Shuling Zhang (D) *a
This study proposes an efficient method for fabricating a light weight and flexible composite film with excellent thermal stability and mechanical properties for wide-band electromagnetic interference (EMI) shielding, which was prepared by melt blending and subsequent melt extrusion using poly(ether ether ketone) (PEEK) as a matrix, multi-walled carbon nanotube wrapped poly(ether sulfone) (wrapped MWCNTs) as a conductive filler, and GENIOPLAST® PELLET S (GPPS, high-temperature lubricant) as a processing aid. GPPS was firstly used in EMI application, to reduce the melt viscosity of PEEK as well as to improve the dispersion of wrapped MWCNTs, which enables it to fabricate a highly efficient EMI shielding ( 74.6 dB mm ${ }^{-1}$ ) PEEK/wrapped MWCNT/GPPS1.0 composite film with a thickness of $180 \mu \mathrm{m}$. Furthermore, the lightweight composite film exhibits high thermal stability (i.e. degradation temperature at $5 \%$ mass loss of $586^{\circ} \mathrm{C}$ ) and good mechanical properties (tensile strength of $101 \mathrm{MPa}$ ), being superior to other previously reported EMI shielding films. The above mentioned enhanced property demonstrated its potential application as a high performance EMI shield for certain applications such as in the aerospace, weapons, and microelectronics industries, which require materials exhibits EMI shielding as well as superior mechanical properties and thermal stability.
\end{abstract}

\section{Introduction}

The advent of wireless communication has dramatically increased the use of electronic devices in both commercial and military sectors. ${ }^{\mathbf{1 , 2}}$ However, the high-frequency electromagnetic (EM) radiation (megahertz to gigahertz) emitted by these devices interferes with nearby equipment and causes its malfunction or breakdown, thus requiring wide-band EM radiation shielding to avoid EM interference (EMI) and keep working environments safe.,4 Although metals are commonly used as EMI shielding materials, ${ }^{5,6}$ their numerous drawbacks such as high density, poor mechanical flexibility, being prone to corrosion and processing difficulties limit their use in modern electronics. $^{7,8}$ In addition, metals are highly microwave-

${ }^{a}$ National \& Local Joint Engineering Laboratory for Synthesis Technology of High Performance Polymer, College of Chemistry, Jilin University, Changchun, 130012, P. R. China. E-mail: zsl@jlu.edu.cn; Fax: +8643185168868; Tel: +8643185168868

${ }^{b}$ Changchun Applied Chemistry Corporation Chinese Academy of Sciences, Changchun, 130012, P. R. China

$\dagger$ Electronic supplementary information (ESI) available: The dimensions of film samples in EMI shielding test; TGA curves of PEEK/MWCNT composites with different GPPS contents; comparisons of AC conductivities and thermal stabilities between PEEK/MWCNT/GPPS1.0 and PEEK/wrapped MWCNT/GPPS1.0 composite films; the detailed EMI SE and specific EMI SE of PEEK/wrapped MWCNT/GPPS1.0 film (9 wt\% wrapped MWCNT) at various frequencies. See DOI: 10.1039/c7ra11675f reflective, shielding only devices enclosed within them and failing to protect the working environment. The above mentioned problems can be solved by the development of materials capable of absorbing EM radiation, e.g., thin and easily foldable EMI shielding films, which can find applications in prospective flexible electronics such as foldable phones, electronic paper displays, and wearable devices. Up to now, much effort has been directed at developing thin, lightweight, flexible, and corrosion-resistant new-generation smart materials capable of strong EM radiation absorption over a wide frequency range. ${ }^{\mathbf{9 , 1 0}}$

Compared to conventional metal based EMI shielding materials, polymer composites containing carbon-based conductive fillers exhibit the advantages of being lightweight, flexible, corrosion-resistant, and easily processable. ${ }^{\mathbf{1 1 2} 12}$ Specifically, multi-walled carbon nanotubes (MWCNTs) are excellent fillers for EMI shielding materials owing to their unique electrical, mechanical, and thermal properties. ${ }^{\mathbf{1 3 - 1 5}}$ However, certain applications (e.g., aerospace, weapons, vehicles, and microelectronics) requiring materials with superior mechanical properties and thermal stability necessitate the use of highperformance polymers instead of general ones. Poly(ether ether ketone) (PEEK) is a semi-crystalline thermoplastic, high performance engineering polymer with superior mechanical properties, thermal stability, and corrosion resistance, being 
frequently used in the aerospace industry and electronics. ${ }^{\mathbf{1 6 - 2 0}}$ More importantly, PEEK/MWCNT composite films can meet the requirements imposed on next-generation EMI shielding materials even in harsh environment.

The fact that MWCNTs are prone to agglomeration and are difficult to disperse in PEEK complicates, which restrict their use in EMI shielding materials. ${ }^{21}$ To solve this problem, we used MWCNTs wrapped in poly(ether sulfone) (noted as wrapped MWCNT) as a filler and a high-melt-index/low-melt-viscosity PEEK as matrix in our previous study, owing to the interaction between $\pi$-bonded surface of MWCNTs and the aromatic structure of the PES, the PES firm coating on the MWCNTs, which effectively avoiding the MWCNT agglomeration; secondly, the molecular structure of PES is similar to that of PEEK, which further enhancing their dispersibility in PEEK matrix. ${ }^{13,16}$ However, low-melt-viscosity PEEK is not suitable to produce flexible and thin composite films, using high-meltviscosity PEEK as film matrix is necessary and still a challenge, since the low melt index and high melt viscosity properties of the high-melt-viscosity PEEK severely lead to failure of the filler dispersion and film processing. Besides, the EMI shielding effectiveness (EMI SE) of materials has mostly been evaluated in a narrow frequency range (8-12 GHz, $\mathrm{X}$ band), ${ }^{22-25}$ necessitating the development of advanced materials with good EMI SE in a wider frequency range of 8-40 GHz, which covers the bands used by civil, commercial, and military applications. $^{20}$

In the present study, a series of PEEK/wrapped MWCNT/ GENIOPLAST® PELLET S (GPPS) composite films with high flexible, good thermal and mechanical properties were prepared and applied to EMI shielding materials for the first time. PES was chosen as a coating for MWCNTs to ensure their strong interfacial adhesion and good dispersibility in PEEK matrix. Besides, we used a high-temperature lubricant, GPPS, in PEEK/ wrapped MWCNT composites, which is an important siliconebased processing additive used in thermoplastics compounding in the plastics industry, for decreasing the melt viscosity of composites. In this system, the GPPS effectively reduce the melt viscosity of PEEK and further improve the dispersion of wrapped MWCNTs therein, to make it possible for the preparation of light weight and flexible PEEK/wrapped MWCNT/GPPS composite films, and improves the EMI SE in a wider frequency range of $8-40 \mathrm{GHz}$ at the same time. The EMI SE, electrical conductivity, mechanical properties, and thermal stability of PEEK/wrapped MWCNT/GPPS composite films were discussed detailed in this study.

\section{Experimental}

\subsection{Materials}

PEEK (melt flow index: $25 \mathrm{~g} 10 \mathrm{~min}^{-1}$ ) and poly(ether sulfone) (PES, inherent viscosity: $0.34 \mathrm{dL} \mathrm{g}^{-1}$ ) powders were purchased from Jilin University Super Engineering Plastics Research Co., Ltd. (China). MWCNTs (outside diameter $=10-20 \mathrm{~nm}$, length $=$ 10-30 $\mu \mathrm{m}$, purity > $95 \mathrm{wt} \%$, grown by chemical vapor deposition) were supplied by Chengdu Organic Chemicals Co., Ltd. (China). Granular GENIOPLAST® Pellet S (GPPS) supplied by
Wacker Co., Ltd. (Germany), which was ground into a powder before compounding.

\subsection{Preparation of PEEK/MWCNT-GPPS composites}

PEEK powder (93 wt\%), MWCNTs (7 wt \%), and GPPS $(0,0.4,0.7$, 1.0, 2.5, and $5.0 \mathrm{wt} \%$ of the total weight of PEEK and MWCNTs) were pre-mixed using a high-speed mixer.

PEEK/MWCNT composites without and with GPPS were prepared by using a Mini-Haake co-rotating twin-screw extruder (Thermo Fisher Scientific, Waltham, Massachusetts, USA) at a screw speed of $40 \mathrm{rpm}$ and a temperature of $390{ }^{\circ} \mathrm{C}$. The obtained samples were noted as PEEK/MWCNT composite-GPPS $x$, where $x$ is weight percent of the GPPS in the total PEEK and MWCNTs. The composites were cut into granules, then dried at $100{ }^{\circ} \mathrm{C}$ for $6 \mathrm{~h}$ in a vacuum oven, and then molded with the HAAKE MiniJet at a temperature of $400{ }^{\circ} \mathrm{C}$ and a pressure of $82 \mathrm{MPa}$ for different measurements.

\subsection{Preparation of wrapped MWCNTs}

The wrapped MWCNTs was obtained following the procedure in our previous study. ${ }^{13}$ Briefly, PES powder was dissolved in dimethylacetamide (DMAc), and MWCNTs were added upon stirring. The resulting mixture was poured into deionized water several times to remove DMAc, affording wrapped MWCNTs.

\subsection{Preparation of PEEK/wrapped MWCNT/GPPS composite films}

PEEK powder (99, 97, 95, 93, and $91 \mathrm{wt} \%$ ), wrapped MWCNTs $(1,3,5,7$, and $9 \mathrm{wt} \%)$, and GPPS ( $1 \mathrm{wt} \%$ of the total weight of PEEK and wrapped MWCNTs) were pre-mixed using a highspeed mixer.

The above mixture was melt-blended (Haake PTW16/25p corotating twin-screw extruder, screw speed $=80 \mathrm{rpm}$, temperature profile $=270 / 350 / 355 / 360 / 365 / 360{ }^{\circ} \mathrm{C}$ ) and granulated, with the obtained granules subsequently dried at $100{ }^{\circ} \mathrm{C}$ for $4 \mathrm{~h}$.

Next, PEEK/wrapped MWCNT/GPPS composite films were fabricated by melt extrusion of dried granules using an arcuateslit-head extruder at a screw speed of $120 \mathrm{rpm}$, a temperature profile of $270 / 350 / 360 / 365 / 370 / 380{ }^{\circ} \mathrm{C}$, and a three-roller calender stretching speed of $2 \mathrm{~m} \mathrm{~min}^{-1}$.

It should be noted that the above molding process generally becomes very difficult at MWCNTs contents above $9 \mathrm{wt} \%$, the composite films become discontinuous or uneven due to the increased filler content. Hence, the loading of wrapped MWCNTs did not exceed $9 \mathrm{wt} \%$ in this study.

\subsection{Characterizations}

Morphologies of fractured composites and film surfaces (goldsputtered before scanning) were observed by field emission scanning electron microscopy (FE-SEM; FEI Nova Nano 450) and Superscan scanning electron microscope (SEM; Shimadzu SSX-550), respectively.

Electrical conductivity measurements were performed at room temperature in a frequency range of $10^{2}-10^{6} \mathrm{~Hz}$ using an Agilent 4294A precision impedance analyzer. The composites 
and films were cut into round specimens with a diameter of 10 $\mathrm{mm}$, and two opposite surfaces of specimens were coated with silver conductive glue to ensure their good contact with electrodes.

The EMI SE of produced films was calculated based on vector scattering parameters $S_{11}$ (as a measure of the forward reflection coefficient) and $S_{21}$ (as a measure of the forward transmission coefficient), which were measured using an N5244A PNA vector network analyzer (Agilent, USA). For EMI shielding test, all film samples were cut into rectangular shapes, the film had a thickness of $\sim 180 \mu \mathrm{m}$, and the precisely dimensions at different frequency band are shown in Table $\mathrm{S} 1 . \dagger$

The densities $\left(\mathrm{g} \mathrm{cm}^{-3}\right)$ of composite film were measured by buoyancy method, using an electronic densimeter (SD-200L), from Alfa Mirage Co., Ltd, Japan. The composite films were cut into square shapes with a size of $20 \mathrm{~mm} \times 20 \mathrm{~mm} \times 0.18$ $\mathrm{mm}$, and each film sample was tested three times.

Tensile testing was conducted on a Shimadzu AG-1 universal testing machine at room temperature and a rate of $5 \mathrm{~mm} \mathrm{~min}{ }^{-1}$, and tensile strength and elongation at break were also obtained from stress-strain curves. The gauge length, width and thickness of the test samples were $18.00 \mathrm{~mm} \times 4.00 \mathrm{~mm} \times 2.00 \mathrm{~mm}$ (length $\times$ width $\times$ thickness, for composites) and $18.00 \mathrm{~mm} \times$ $4.00 \mathrm{~mm} \times 0.18 \mathrm{~mm}$ (length $\times$ width $\times$ thickness, for composite films), respectively. The results of each composition were reported as average of at least three samples tests.

Thermogravimetric analysis (TGA) of composites and films were performed in air atmosphere, using a Perkin Elmer Pryis 1 TGA analyzer. For each measurement, $6 \pm 1 \mathrm{mg}$ of sample was heated at a heating rate of $10{ }^{\circ} \mathrm{C} \mathrm{min}^{-1}$.

\section{Results and discussion}

The improvement in the dispersibility of the filler in the polymer matrix can be achieved not only by adjusting the melt index of the polymer matrix and by modifying the filler, but also by the addition of a suitable amount of processing aid GPPS. Thus, the PEEK/MWCNT composite-GPPS $x$ were prepared, and their frequency dependence of the room-temperature alternating current (AC) conductivity are shown in Fig. 1a. The conductivity of the PEEK/MWCNT composite without GPPS was about $3.5 \times$ $10^{-2} \mathrm{~S} \mathrm{~m}^{-1}$. With an increase of the content of GPPS from $0.4 \mathrm{wt} \%$ to $1.0 \mathrm{wt} \%$, the conductivity of the PEEK/MWCNT composite-GPPS gradually increased. Moreover, the conductivity increased to $8.9 \times 10^{-2} \mathrm{~S} \mathrm{~m}^{-1}$ after introduction of $1.0 \mathrm{wt} \%$ GPPS, which is an increase of about $154 \%$. However, with a further increase of the content of GPPS to $2.5 \mathrm{wt} \%$ and $5.0 \mathrm{wt} \%$, the conductivity decreased to $8.8 \times 10^{-2} \mathrm{~S} \mathrm{~m}^{-1}$ and 7.8 $\times 10^{-2} \mathrm{~S} \mathrm{~m}^{-1}$, respectively. It could be seen that the conductivity of the PEEK/MWCNT composite-GPPS shows an initial increase, followed by a decrease as the weight fraction of GPPS increases. The highest conductivity was achieved with the PEEK/MWCNT composite-GPPS1.0 containing $1.0 \mathrm{wt} \%$ GPPS.

The changes in the conductivity of the PEEK/MWCNT composite-GPPS depend on the dual roles of GPPS. On the one hand, the dispersion of the MWCNTs in the PEEK matrix could be improved as the content of GPPS in the composite
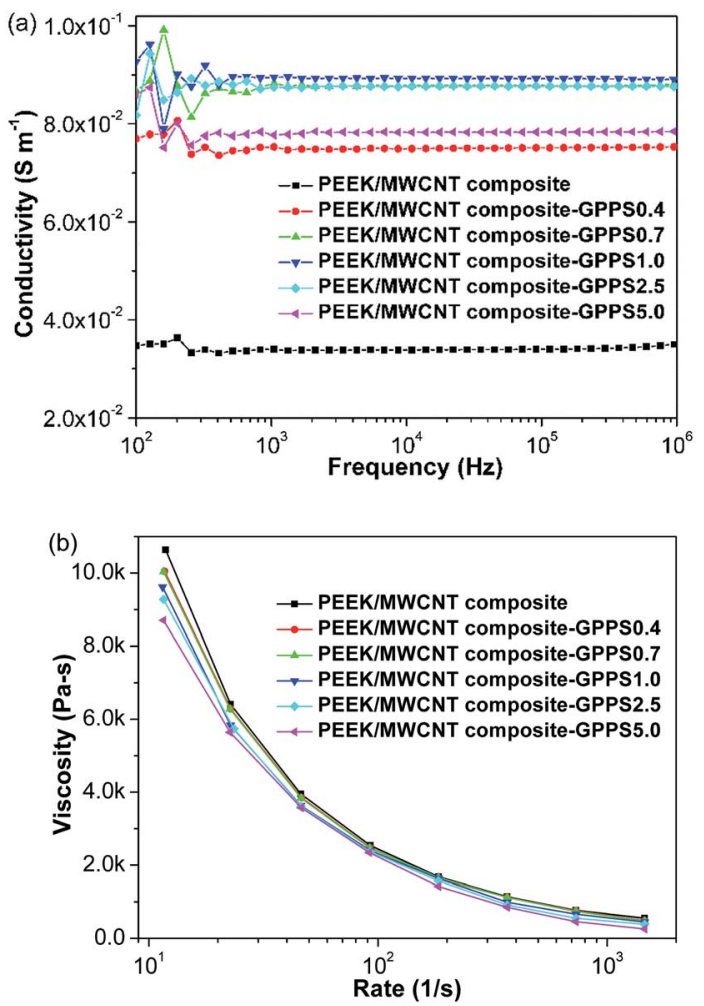

Fig. 1 (a) Dependence of AC conductivity of PEEK/MWCNT composite-GPPSx on frequency at room temperature. (b) Dependence of shear viscosity of PEEK/MWCNT composite-GPPS $x$ on shear rate at $400^{\circ}$

increased, thereby increasing the conductivity of the composite. On the other hand, the content of MWCNTs dispersed in the PEEK matrix was reduced as the content of GPPS increased, due to the intrinsic insulativity of the GPPS, thus the conductivity of the PEEK/MWCNT composite-GPPS $x$ decreased. A balance between these two effects is achieved with the optimal loading of GPPS of $1.0 \mathrm{wt} \%$, which suggests that a small amount of GPPS (1.0 wt\%) was sufficient to enhance the conductivity of the PEEK/MWCNT composites. Furthermore, the conductivity of the composites became independent of frequency in the range of $10^{2}-10^{6} \mathrm{~Hz}$. This may be because the content of MWCNTs was sufficient to effectively provide a tunnel for hopping of the electrons.

The high melt viscosity of PEEK with the low melt index generally lead to failure of the filler dispersion and processing; this disadvantage severely limits the applicability of this material. High-temperature lubricant GPPS is an important processing agent in decreasing the melt viscosity of composites. On the one hand, it can reduce the entanglement between the polymer chains, which helps to decrease the melt viscosity and achieve the better dispersion of filler in polymer matrix; on the other hand, it can decrease the friction between the composites and processing equipment which contributes to the improvement in the processability of flexible and thin composite films. Fig. 1b shows the shear viscosity of the PEEK/MWCNT composite-GPPS $x$ without and with GPPS versus the shear 
rate, and the afore-mentioned phenomenon is substantiated by the data in this figure. The addition of GPPS evidently reduces the melt viscosity of the PEEK/MWCNT composite-GPPS $x$. Moreover, the shear viscosity of the PEEK/MWCNT compositeGPPS $x$ composite gradually decreased with increasing GPPS content. Therefore, the addition of GPPS helps to decrease the melt viscosity in the processing temperature range of the PEEK/ MWCNT composite, leading to better dispersion of the MWCNTs in the PEEK matrix and higher electrical conductivity of the PEEK/MWCNT composite.

To further illustrate the effect of the GPPS on the conductivity and melt viscosity of the PEEK/MWCNT composite, the detailed observation of the cross-section morphology of the PEEK/MWCNT composite and PEEK/MWCNT compositeGPPS1.0 were carried out and shown in Fig. 2. The dispersion of the MWCNTs in the PEEK/MWCNT composite without GPPS was relatively inhomogeneous (Fig. 2a), and the place without MWCNTs has been marked in the figure. In contrast, the MWCNTs are found to be homogenously dispersed in the PEEK/ MWCNT composite-GPPS1.0 matrix (Fig. 2b), and almost no obvious aggregation of the MWCNTs was observed due to the regulation of the viscosity of GPPS. That is, the decrease in the melt viscosity of the PEEK matrix facilitates dispersion of the MWCNTs, thus improves the conductivity of the composites. This is in accordance with the changes in the conductivity and melt viscosity of the PEEK/MWCNT composite-GPPS without and with GPPS.

The effect of GPPS on the mechanical properties of the PEEK/ MWCNT composite were evaluated based on analysis of the tensile strength and elongation at break of the composites. The mechanical properties of the PEEK/MWCNT composite-GPPS $x$ are summarized in Table 1 . Generally, any aggregation of the MWCNTs could result in structural defects with detrimental effects on the mechanical properties. ${ }^{26}$ From Table 1 , it could be found that the tensile strength of the composites remained almost unchanged $(115 \mathrm{MPa})$ with increase of the content of GPPS from 0 to $1.0 \mathrm{wt} \%$. However, with a further increase of the content of GPPS to $2.5 \mathrm{wt} \%$ and $5.0 \mathrm{wt} \%$, the tensile strength decreased to $112 \mathrm{MPa}$ and $108 \mathrm{MPa}$, respectively. In addition, the elongation at break initially increased and then decreased, when the content of GPPS increased from $0.0 \mathrm{wt} \%$ to $0.7 \mathrm{wt} \%$, the elongation at break of the composites increased from $37.2 \%$ to $46.4 \%$. However, the elongation at break gradually decreased from $45.1 \%$ to $35.1 \%$ with the amount of GPPS increased from $1.0 \mathrm{wt} \%$ to $5.0 \mathrm{wt} \%$.
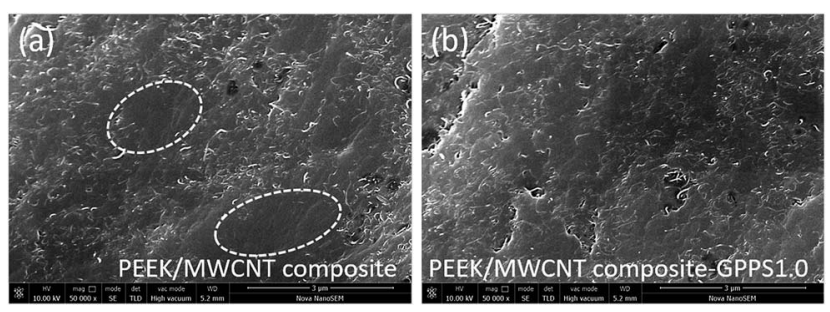

Fig. 2 SEM image of cross-section surface of (a) PEEK/MWCNT composite and (b) PEEK/MWCNT composite-GPPS1.0 (scale bar $=3$ $\mu \mathrm{m})$.
Table 1 Mechanical properties of PEEK/MWCNT composite-GPPSx

\begin{tabular}{lll}
\hline $\begin{array}{l}\text { Amount of GPPS } \\
(\mathrm{wt} \%)\end{array}$ & $\begin{array}{l}\text { Tensile strength } \\
(\mathrm{MPa})\end{array}$ & $\begin{array}{l}\text { Elongation at } \\
\text { break }(\%)\end{array}$ \\
\hline 0 & 115 & 37.2 \\
0.4 & 115 & 38.8 \\
0.7 & 115 & 46.4 \\
1.0 & 115 & 45.1 \\
2.5 & 112 & 37.7 \\
5.0 & 108 & 35.1
\end{tabular}

The changes in the mechanical properties of the PEEK/ MWCNT composites depend on the dual roles of GPPS. On the one hand, the dispersion of the MWCNTs in the PEEK matrix were improved as the content of GPPS increases, i.e., the stress concentration of the PEEK/MWCNT composites was reduced during the tensile test, thereby increasing the tensile strength and elongation at break of the PEEK/MWCNT composites. On the other hand, the lower strength and toughness of GPPS as a processing aid becomes dominant with increasing content of GPPS higher than $1.0 \mathrm{wt} \%$, thus the tensile strength and elongation at break of the PEEK/MWCNT composites decreases. Based on these two effects, it can be indicated that only a suitable amount of GPPS (1.0 wt\%) was sufficient to enhance the electrical conductivity and mechanical properties of the PEEK/MWCNT composites.

The effect of adding GPPS to the composite on the thermal stability of the PEEK/MWCNT composite-GPPS $x$ were evaluated via TGA under air atmosphere. Fig. 3 shows the thermal degradation curves of the PEEK/MWCNT composite and PEEK/ MWCNT composite-GPPS1.0. The addition of GPPS did not impact the thermal stability of the PEEK/MWCNT composite. The temperature of $5 \%$ weight loss $\left(T_{\mathrm{d} 5 \%}\right)$ of the PEEK/MWCNT composite-GPPS1.0 is about $595{ }^{\circ} \mathrm{C}$, which is almost equal to that of the PEEK/MWCNT composite. This phenomenon proves that the addition of GPPS did not produce a negative effect on the thermal stability of the PEEK/MWCNT composites, this can be ascribed to restriction of the thermal motion of the PEEK chains due to the better dispersion of the MWCNTs, thereby

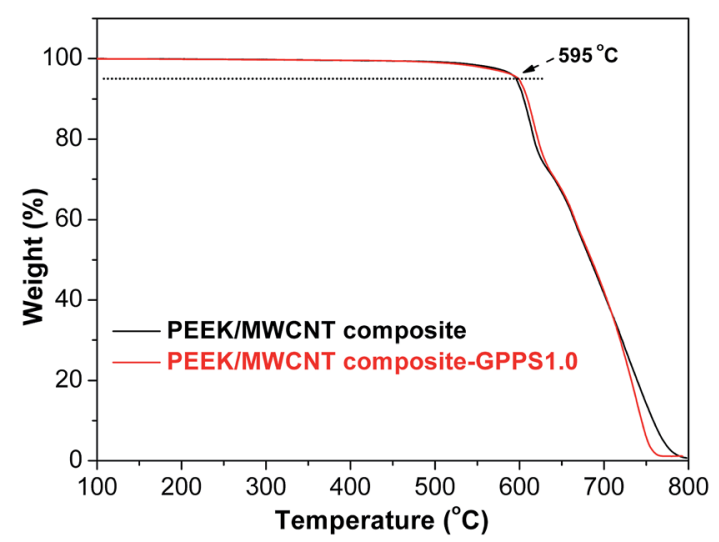

Fig. 3 TGA curves of PEEK/MWCNT composite and PEEK/MWCNT composite-GPPS1.0. 
leading to higher thermal stability of the composites. The TGA curves of PEEK/MWCNT composite-GPPS $x$ with different GPPS contents are given in Fig. S1. $\dagger$

The above mentioned experimental data show that the addition of $1.0 \mathrm{wt} \%$ GPPS could effectively improve the electrical and mechanical properties of PEEK/MWCNT composite and not affecting its thermal stability, thus, the $1.0 \mathrm{wt} \%$ GPPS was chosen as the optimism constituent for further intensively studied.

In our previous study, we designed a EMI SE material, using poly(ether sulfone) (PES) wrapped MWCNTs (noted as wrapped MWCNTs) as conductive filler and dispersed in a high-meltindex/low-melt-viscosity PEEK matrix by melt-blending method, the MWCNTs wrapped in PES efficiently minimizing the agglomeration of MWCNT and enhancing their dispersibility, unfortunately, high-melt-index/low-melt-viscosity PEEK matrix used was not suitable for producing polymer films. ${ }^{13}$ In this study, a low-melt-index/high-melt-viscosity PEEK matrix was adopted to meet requirements of preparation PEEKbased composite films. However, high-melt-viscosity is not conducive to, even more harmful to the dispersion of MWCNTs for PEEK. In order to improve the dispersibility of MWCNTs in the high-melt-viscosity PEEK matrix, MWCNTs were modified by PES as well as addition of $1.0 \mathrm{wt} \%$ GPPS. We compared the conductivities and thermal properties of the PEEK/wrapped MWCNT/GPPS1.0 composite film with PEEK/MWCNT/GPPS1.0 composite film (both two kinds of composite films contain $1 \mathrm{wt} \%$ GPPS, and the weight ratio of the wrapped MWCNT or MWCNT are $7 \mathrm{wt} \%$ ), the comparison results are shown in Fig. S2. $\uparrow$ From Fig. S2, $\uparrow$ it could be seen that the usage of PES wrapped MWCNTs can significantly enhance the conductivity of PEEK/MWCNT/GPPS1.0 composite film, which should be ascribed that the modification of PES on MWCNTs can avoid MWCNTs agglomeration and improve the dispersion of MWCNTs in PEEK. Additionally, the introduction of PES slightly decrease the thermal stability of PEEK/wrapped MWCNT/ GPPS1.0 composite film, but its $T_{\mathrm{d} 5 \%}$ is still up to $583{ }^{\circ} \mathrm{C}$, namely PEEK/wrapped MWCNT/GPPS1.0 composite film also possesses good thermal stability. Thus, to prepare composite film with high shielding effectiveness as well as enough thermal stability and mechanical properties, we choose wrapped MWCNTs as conductive filler, and $1.0 \mathrm{wt} \%$ GPPS as a processing aid, doing further investigation.

Fig. 4a shows room-temperature AC conductivities of PEEK/ wrapped MWCNT/GPPS1.0 composite films as functions of frequency, with different PEEK/wrapped MWCNT proportion (PEEK wt\%/wrapped MWCNT wt $=100 / 0-91 / 9)$. The conductivities of composite films were significantly improved with increasing filler loading, and attained $1.29 \mathrm{~S} \mathrm{~m}^{-1}$ when the wrapped MWCNT up to $9 \mathrm{wt} \%$. In addition, the conductivity of PEEK films increased with increasing frequency, implying insulating behavior. However, 1 wt $\%$ composite film showed a plateau followed by a gradual conductivity increase with increasing frequency, indicative of semiconducting behavior. At MWCNT loadings above $3 \mathrm{wt} \%$, the conductivities of composite films became independent of frequency in the range of $10^{2}-$ $10^{6} \mathrm{~Hz}$, which was mainly attributed to the fact that a certain


Fig. 4 (a) Electrical conductivities on frequency and (b) TGA curves of PEEK/wrapped MWCNT/GPPS1.0 composite films with different PEEK/ wrapped MWCNT proportion.

content of wrapped MWCNTs was sufficient for them to interconnect and form conductive networks in the insulating PEEK matrix.

Thermal stability is an important parameter affecting the operational life of EMI shielding materials. Therefore, we investigated the thermal stabilities of the above mentioned PEEK/wrapped MWCNT/GPPS1.0 composite films by TGA test in air atmosphere. Fig. 4b illustrates the TGA curves of composite films with different wrapped MWCNT contents. The initial decomposition curves of composite films were shifted to higher temperature with the addition of MWCNTs, implying the increased thermal stabilities of the composite films. This phenomenon was rationalized as follows, on the one hand, MWCNTs possess good thermal stability, ${ }^{27}$ with their decomposition temperature of greater than $600{ }^{\circ} \mathrm{C}$, exceeding that of pure PEEK; on the other hand, the network structure formed by MWCNTs in the PEEK matrix hinders the thermal motion of PEEK chains, thereby enhancing the thermal stability of PEEK. The $5 \%$ weight loss temperature $\left(T_{5 \%}\right)$ of composite films with 9 wt $\%$ wrapped MWCNT exceeded $586{ }^{\circ} \mathrm{C}$, indicating their superior thermal stability.

Since the good mechanical properties and light-weight are important indicators determining the practical application of the films, the tensile strength, elongation at break and density of PEEK/wrapped MWCNT/GPPS1.0 composite films were evaluated and illustrated in Table 2. 
Table 2 Mechanical properties and densities of PEEK/wrapped MWCNT/GPPS1.0 composite films

\begin{tabular}{llll}
\hline $\begin{array}{l}\text { PEEK/wrapped } \\
\text { MWCNT (wt\%/wt\%) }\end{array}$ & $\begin{array}{l}\text { Tensile strength } \\
(\mathrm{MPa})\end{array}$ & $\begin{array}{l}\text { Elongation at } \\
\text { break (\%) }\end{array}$ & $\begin{array}{l}\text { Density } \\
\left(\mathrm{g} \mathrm{cm}^{-3}\right)\end{array}$ \\
\hline $100 / 0$ & 89 & 180 & 1.2776 \\
$99 / 1$ & 110 & 156 & 1.2932 \\
$97 / 3$ & 109 & 128 & 1.3028 \\
$95 / 5$ & 105 & 80 & 1.3150 \\
$93 / 7$ & 102 & 62 & 1.3247 \\
$91 / 9$ & 101 & 53 & 1.3380 \\
\hline
\end{tabular}

The tensile strength of composite films exceeded that of pure PEEK film, whereas an opposite trend was observed for elongation at break, which was explained as follows, on the one hand, MWCNTs increase the strength of composite films; on the other hand, the addition of MWCNTs decreases matrix crystallinity and increases the amount of structural defects. ${ }^{13}$ Overall, the prepared composite films exhibited relatively good mechanical properties, which was attributed to the homogeneous dispersion and good interfacial adhesion discussed above. The densities of PEEK and its composite films gradually increased with increasing filler content but did not exceed $1.34 \mathrm{~g} \mathrm{~cm}^{-3}$ for all films. Compared to conventional metalbased EMI shielding materials such as nickel-copper alloys with densities as high as $8.6 \mathrm{~g} \mathrm{~cm}^{-3}$, PEEK/wrapped MWCNT/ GPPS1.0 composite films exhibited the advantage of combining low density with relatively high EMI SE.

The EMI SE of PEEK/wrapped MWCNT/GPPS1.0 composite films were measured at frequencies of $8.2-40 \mathrm{GHz}$ to evaluate the effects of the wrapped MWCNTs and GPPS, which was determined by scattering parameters, according to the equation:

$$
\text { EMI SE }=-10 \lg \left|S_{21}\right|^{2}=\frac{P_{\text {out }}}{P_{\text {in }}}
$$

where $P_{\text {in }}$ and $P_{\text {out }}$ stand for incident and transmission power, respectively. It should be noted that EMI SE was positively influenced by film thickness, the EMI SE increases as the thickness of the sample increase, thus, to compare the EMI SEs of films more directly and convenient, specific EMI SE was calculated by dividing the thickness of the composite membrane, and the results are shown in Fig. 5b. As shown in Fig. 5a, the SE of the PEEK/wrapped MWCNT/GPPS1.0 composite films were significantly increasing with the wrapped MWCNT loading. This observation was explained by the fact that increased filler content increases the number of interconnected wrapped MWCNTs, interacting with the incident electromagnetic waves and thus results in higher SE. In addition, the SE of all films was almost independent of frequency. The average SE of pure PEEK film equaled only 0.05 $\mathrm{dB},{ }^{13}$ whereas that of the composite film with a $9 \mathrm{wt} \%$ filler loading equaled $10.5 \mathrm{~dB}$, corresponding to $91 \%$ shielding. The high performance of composite film was mainly due to the good dispersion of wrapped MWCNTs under the help of the GPPS, which allowed conductive networks to be formed in the
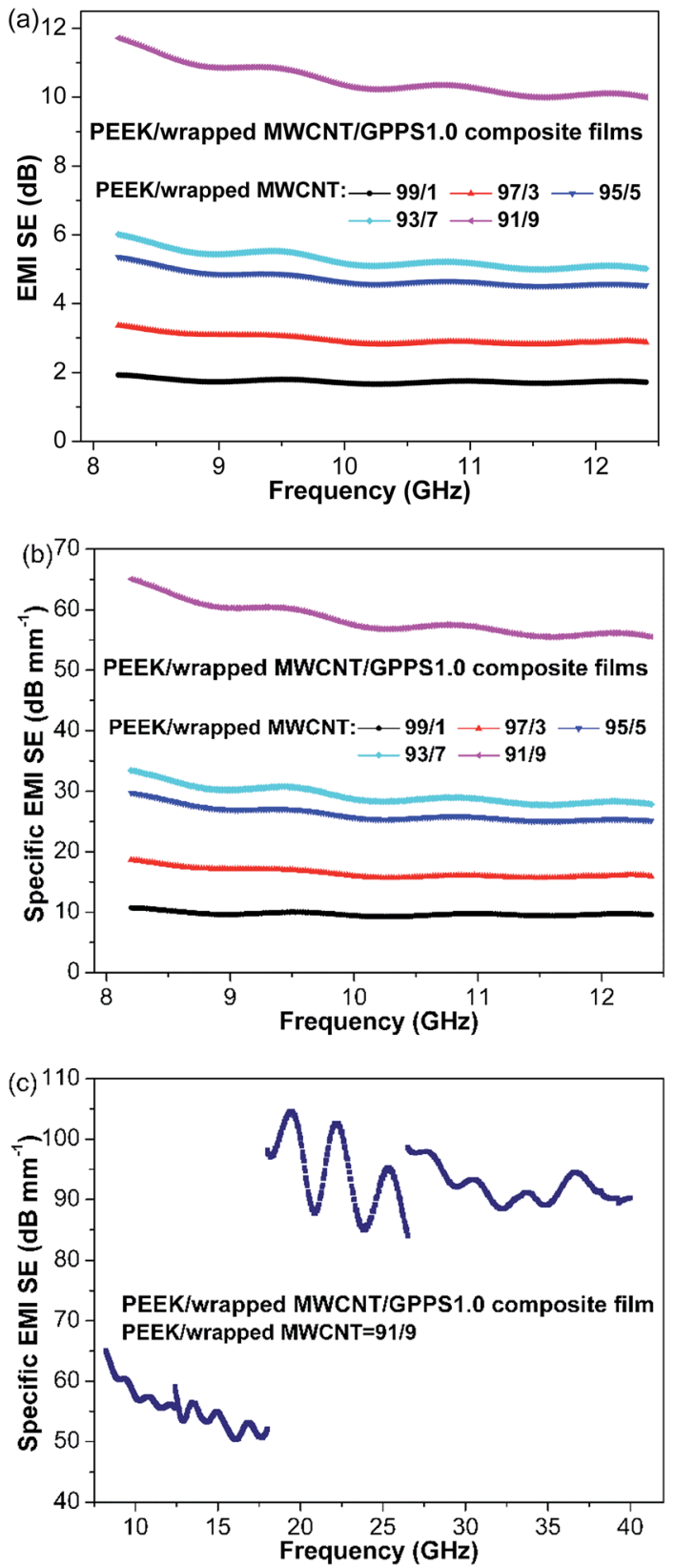

Fig. 5 (a) EMI SE and (b) specific EMI SE for PEEK/wrapped MWCNT/ GPPS1.0 composite films with different PEEK/wrapped MWCNT proportion at frequencies of $8.2-12.4 \mathrm{GHz}$. (c) Specific EMI SE of PEEK/ wrapped MWCNT/GPPS1.0 composite films ( 9 wt\% wrapped MWCNT) in four frequency ranges of $8.2-12.4 \mathrm{GHz}$ (X band), $12.4-18 \mathrm{GHz}(\mathrm{Ku}$ band), $18-26.5 \mathrm{GHz}$ (K band), and $26.5-40 \mathrm{GHz}$ (Ka band).

insulating PEEK matrix. Generally, electromagnetic waves incident on the surface of shielding materials give rise to the phenomena of reflection (R), absorption (A), and transmission (T), with the overall SE being the sum of reflection and absorption ( $\mathrm{SE}_{\mathrm{R}}$ and $\mathrm{SE}_{\mathrm{A}}$, respectively), i.e., $\mathrm{SE} \approx \mathrm{SE}_{\mathrm{R}}+\mathrm{SE}_{\mathrm{A}}$. The PEEK/wrapped MWCNT/GPPS1.0 composite films (9 wt\% wrapped MWCNT) used herein exhibited average $\mathrm{SE}, \mathrm{SE}_{\mathrm{R}}$, and $\mathrm{SE}_{\mathrm{A}}$ of $10.5,3.3$, and $7.2 \mathrm{~dB}$ at $8.2-12.4 \mathrm{GHz}$, respectively, implying the dominance of absorption over reflection and 
Table 3 A comparison of the average total EMI SE, tensile strength and $T_{5 \%}$ values of various reported composite materials with the present work under optimal conditions

\begin{tabular}{|c|c|c|c|c|c|c|c|}
\hline Material & $\begin{array}{l}\text { Frequency } \\
(\mathrm{GHz})\end{array}$ & $\mathrm{SE}(\mathrm{dB})$ & $\begin{array}{l}\operatorname{SSE}^{a} \\
\left(\mathrm{~dB} \mathrm{~mm}^{-1}\right)\end{array}$ & $\begin{array}{l}\text { Thickness } \\
(\mathrm{mm})\end{array}$ & $\begin{array}{l}\text { Tensile strength } \\
(\mathrm{MPa})\end{array}$ & $T_{5 \%}{ }^{b}\left({ }^{\circ} \mathrm{C}\right)$ & Reference \\
\hline PEEK/wrapped MWCNT/GPPS1.0 & $8.2-12.4$ & $\sim 10.5$ & 58.3 & 0.18 & 101 & 586 & This work \\
\hline PEEK/wrapped MWCNT & $12.0-18.0$ & $\sim 55$ & $\sim 27.5$ & 2 & 91 & 583 & 13 \\
\hline $\mathrm{Fe}_{3} \mathrm{O}_{4} @ P A N I /$ polyazomethine/PEEK & $2.0-18.0$ & $\sim 10$ & 5 & 2 & 11.17 & $\sim 300$ & 28 \\
\hline $\mathrm{PANI}-\mathrm{CNT} / \mathrm{PS}^{c}$ & $12.4-18$ & $\sim 24$ & 24 & 1 & - & - & 29 \\
\hline Poly lactide/graphene nanoplatelet & 9.0 & $\sim 14.3$ & 9.53 & 1.5 & - & - & 32 \\
\hline${\mathrm{PC} / \mathrm{MWCNT}^{e}}^{e}$ & 17.5 & 27.2 & 9 & 3 & 72 & - & 33 \\
\hline $\mathrm{PMMA}^{f} / \mathrm{MWCNT}$ & $8.0-12.0$ & 18 & 60.0 & 0.3 & 30 & $\sim 200$ & 34 \\
\hline
\end{tabular}

${ }^{a}$ SSE: specific EMI SE, which was divided by the thickness of the composite film. ${ }^{b} 5 \%$ weight loss temperature in TGA test. ${ }^{c}$ PANI: polyaniline; PS: polystyrene. ${ }^{d}$ PVB: polyvinyl butyral. ${ }^{e}$ PC: polycarbonate. ${ }^{f}$ PMMA: polymethyl methacrylate.

indicating that these films behaved as electromagnetic wave absorbers. Fig. 5c shows specific SE values determined for PEEK/wrapped MWCNT/GPPS1.0 composite film (9 wt\% wrapped MWCNT) in four frequency ranges, namely 8.2-12.4 GHz (X band), $12.4-18 \mathrm{GHz}$ (Ku band), 18-26.5 GHz (K band), and 26.5$40 \mathrm{GHz}$ (Ka band), revealing that these values increased when the frequency range changed from $8.2-18$ to $18-40 \mathrm{GHz}$. For example, the $9 \mathrm{wt} \%$ composite film exhibited an specific SE of $\sim 55.4 \mathrm{~dB} \mathrm{~mm}^{-1}$ in the range of $8.2-18 \mathrm{GHz}$, and was found to increase to $\sim 94.9 \mathrm{~dB} \mathrm{~mm}^{-1}$ in the range of $18-40 \mathrm{GHz}$. The average specific EMI SE was almost $74.6 \mathrm{~dB} \mathrm{~mm}^{-1}$ in the wide range of 8.2-40 GHz. Thus, PEEK/wrapped MWCNT/GPPS1.0 composite films exhibited superior specific EMI SE in a wide frequency range, the detailed EMI SE and specific EMI SE of PEEK/wrapped MWCNT/GPPS1.0 film ( 9 wt $\%$ wrapped MWCNT) at various frequencies are shown in Table S2.† Furthermore, this value is superior to those recently reported EMI SE composite films, a comparison of the EMI shielding property of PEEK/wrapped MWCNT/GPPS1.0 film ( $9 \mathrm{wt} \%$ wrapped MWCNT) with other composite films under optimized conditions is tabulated in Table $3 .^{13,28-34}$

In addition, the prepared PEEK/wrapped MWCNT/GPPS1.0 composite film (9 wt\% wrapped MWCNT) possessed high flexibility. As shown in Fig. 6a, the films can be easily wound into rolls and bent over a large angle, with no cracks and creases

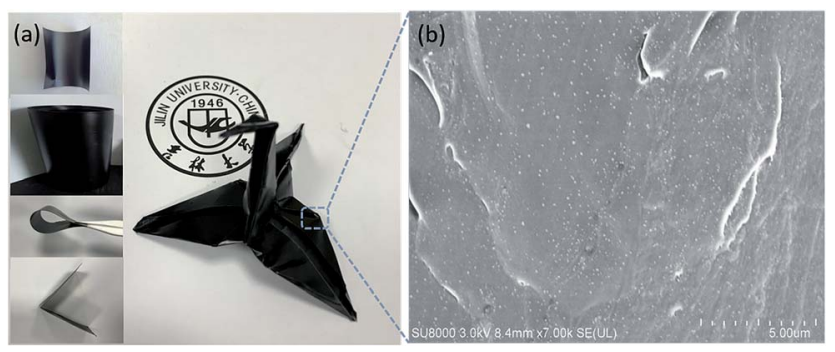

Fig. 6 (a) Digital photographs of a PEEK/wrapped MWCNT/GPPS1.0 composite film with excellent flexibility, i.e., round into a roll, under bending condition and fold into paper crane shape. (b) Cross-section SEM image of composite film. appearing after bending; moreover, due to the excellent flexibility, the film can be fold into various shapes, i.e., paper crane. The properties of composite films were determined by the dispersion of wrapped MWCNTs in the PEEK matrix, since the important features such as conductivity and EMI SE were disrupted by heterogeneity or filler aggregation. Fig. $6 \mathrm{~b}$ shows the cross-section SEM image of PEEK/wrapped MWCNT/GPPS1.0 composite film ( $9 \mathrm{wt} \%$ wrapped MWCNT) with a typical roll and composite film fracture morphology, revealing that the film possessed smooth surface and wrapped MWCNTs were almost uniformly dispersed in PEEK matrix, with no agglomeration or entanglement observed. Besides, no open-ring holes or voids were detected around wrapped MWCNTs, indicating good compatibility and interfacial adhesion between the filler and the matrix. Thus, the relatively good conductivity and EMI SE of PEEK/wrapped MWCNT/GPPS1.0 composite film could be attributed to the addition of a well-dispersible conductive filler (wrapped MWCNTs) and a high-temperature lubricant (GPPS).

\section{Conclusion}

In this study, a flexible and lightweight PEEK/wrapped MWCNT/GPPS1.0 composite film for EMI SE were successfully produced. Due to the well-dispersible conductive filler (wrapped MWCNT) and a high-temperature lubricant (GPPS), the composite film exhibited extremely enhanced EMI SE and electrical conductivities compared to pure PEEK film. Remarkably, at a filler loading of $9 \mathrm{wt} \%$, the electrical conductivity of composite films reached $1.29 \mathrm{~S} \mathrm{~m}^{-1}$ at $10^{3} \mathrm{~Hz}$, with an specific EMI SE of $\sim 74.6 \mathrm{~dB} \mathrm{~mm}^{-1}$, which is superior to those of other polymer-based EMI shielding materials. Importantly, the produced composite films were thin and lightweight, exhibiting high flexibility as well as high mechanical and thermal properties. Based on these reasons, we believe that such a lightweight and flexible composite film with good mechanical properties and thermal stabilities for wide-band EMI shielding can amplify the application scope of PEEK based films for electromagnetic shielding. 


\section{Conflicts of interest}

There are no conflicts to declare.

\section{Acknowledgements}

This work was financially supported by the Jilin Province Science and Technology Development Program of China (No. 20170101109 JC) and Jilin Province Strategic Adjustment of Economic Structure Program of China (No. 2015Y046).

\section{References}

1 T. Zhai, L. Di and D. Yang, ACS Appl. Mater. Interfaces, 2013, 5, 12499-12509.

2 A. Gupta and V. Choudhary, Compos. Sci. Technol., 2011, 71, 1563-1568.

3 Y. Chen, H. B. Zhang, Y. Yang, M. Wang, A. Cao and Z. Yu, Adv. Funct. Mater., 2016, 26, 447-455.

4 Z. Chen, C. Xu, C. Ma, W. Ren and H. M. Cheng, Adv. Mater., 2013, 25, 1296-1300.

5 S. Geetha, K. K. S. Kumar, C. R. K. Rao, M. Vijayan and D. C. Trivedi, J. Appl. Polym. Sci., 2009, 112, 2073-2086.

6 Y. Kato, M. Horibe, S. Ata, T. Yamada and K. Hata, RSC Adv., 2017, 7, 10841-10847.

7 S. Biswas, G. P. Kar and S. Bose, ACS Appl. Mater. Interfaces, 2015, 7, 25448-25463.

8 Y. J. Yim, K. Y. Rhee and S. J. Park, Composites, Part B, 2016, 98, 120-125.

9 A. Kosmala, R. Wright, Q. Zhang and P. Kirby, Mater. Chem. Phys., 2011, 129, 1075-1080.

10 T. Zhai, C. Ding, L. Lu, C. Zhang and D. Yang, Mater. Lett., 2015, 147, 46-49.

11 N. C. Das, T. K. Chaki, D. Khastgir and A. Chakraborty, J. Appl. Polym. Sci., 2001, 80, 1601-1608.

12 S. Yang, K. Lozano, A. Lomeli, H. D. Foltz and R. Jones, Composites, Part A, 2005, 36, 691-697.

13 H. Wang, G. Wang, W. Li, Q. Wang, W. Wei, Z. Jiang and S. Zhang, J. Mater. Chem., 2012, 22, 21232-21237.

14 P. Verma, P. Saini, R. S. Malik and V. Choudhary, Carbon, 2015, 89, 308-317.
15 R. Rohini and S. Bose, ACS Appl. Mater. Interfaces, 2014, 6, 11302-11310.

16 S. Zhang, H. Wang, G. Wang and Z. Jiang, Appl. Phys. Lett., 2012, 101, 012904.

17 L. Yang, S. Zhang, Z. Chen, Y. Guo, J. Luan, Z. Geng and G. Wang, J. Mater. Sci., 2014, 49, 2372-2382.

18 A. M. Díezpascual, M. Naffakh, C. Marco, G. Ellis and M. A. Gómezfatou, Prog. Mater. Sci., 2012, 57, 1106-1190.

19 A. Jonas and R. Legras, Polymer, 1991, 32, 2691-2706.

20 S. S. Chauhan, M. Abraham and V. Choudhary, RSC Adv., 2016, 6, 113781-113790.

21 A. M. Díez, Carbon, 2009, 47, 3079-3090.

22 X. Wei, J. Chen, S. Kundu and M. Muhler, Carbon, 2009, 47, 919-922.

23 A. Fletcher, M. C. Gupta, K. L. Dudley and E. Vedeler, Compos. Sci. Technol., 2010, 70, 953-958.

24 Y. Huang, N. Li, Y. Ma, F. Du, F. Li, X. He, X. Lin, H. Gao and Y. Chen, Carbon, 2007, 45, 1614-1621.

25 A. Joshi, A. Bajaj, R. Singh, A. Anand, P. S. Alegaonkar and S. Datar, Composites, Part B, 2015, 69, 472-477.

26 W. S. Jou, H. Z. Cheng and C. F. Hsu, The electromagnetic shielding effectiveness of carbon nanotubes polymer composites, J. Alloys Compd., 2007, 434, 641-645.

27 A. M. Díez-Pascual, G. Martínez, M. T. Martínez and M. A. Gómeza, J. Mater. Chem., 2010, 20, 8247-8256.

28 W. Wei, X. Yue, Y. Zhou, Y. Wang, Z. Chen, M. Zhu, J. Fang and Z. Jiang, RSC Adv., 2014, 4, 11159-11167.

29 P. Saini, V. Choudhary, B. P. Singh, R. B. Mathur and S. K. Dhawan, Synth. Met., 2011, 161, 1522-1526.

30 J. D. Sudha, S. Sivakala, K. Patel and P. Radhakrishnan Nair, Composites, Part A, 2010, 41, 1647-1652.

31 P. J. Bora, G. Lakhani, P. C. Ramamurthy and G. Madras, RSC Adv., 2016, 6, 79058-79065.

32 S. Kashi, R. K. Gupta, T. Baum, N. Kao and S. N. Bhattacharya, Mater. Des., 2016, 95, 116-126.

33 A. S. Babal, R. Gupta, B. P. Singh, V. N. Singh, S. R. Dhakate and R. B. Mathur, RSC Adv., 2014, 4, 64649-64658.

34 R. B. Mathur, S. Pande, B. P. Singh and T. L. Dhami, Polym. Compos., 2008, 29, 717-727. 